\title{
Association Between Snoring and Diabetes Among Pre- and Postmenopausal Women
}

\author{
Yun Yuan $\mathbb{D}^{\prime}$, Fan Zhang', Jingfu Qiu', Liling Chen², Meng Xiao', Wenge Tang², Qinwen Luo (D)', \\ Xianbin Ding ${ }^{2}$, Xiaojun Tang (iD) \\ 'School of Public Health and Management, Medical and Social Development Research Center, Chongqing Medical University, Chongqing, 4000I6, \\ People's Republic of China; ${ }^{2}$ Chongqing Municipal Center for Disease Control and Prevention, Chongqing, 400042, People's Republic of China \\ Correspondence: Xiaojun Tang, School of Public Health and Management, Medical and Social Development Research Center, Chongqing \\ Medical University, No. I Yixueyuan Road, Yuzhong District, Chongqing, 4000I6, People's Republic of China, Tel +86-I3668023656, \\ Email 100108@cqmu.edu.cn; Xianbin Ding, Chongqing Municipal Center for Disease Control and Prevention, Chongqing, 400042, People's \\ Republic of China, Tel +86-I3896096430, Email xianbinding@I26.com
}

\begin{abstract}
Purpose: To examine the relationship between diabetes and snoring frequency and determine the effect of menopause and postmenopausal years on this relationship.

Methods: We included 12,218 premenopausal and postmenopausal women from part of the baseline of the China Multi-Ethnic Cohort study (CMEC) in Chongqing province. Face-to-face questionnaires, physical examination, and biological samples were used to collect data. Logistic regression and subgroup analysis were used to explore the relationship between snoring and diabetes in women with various menopausal statuses.

Results: The risk of diabetes increased with the snoring frequency, with adjusted odds ratios of 1.23 (95\% CI:1.05-1.43) and 1.47 (95\% CI:1.25-1.73) for sometimes snoring and frequent snoring, compared to non-snoring. In premenopausal and postmenopausal women, frequent snoring increased the odds of diabetes by 58\% (95\% CI: $7-132 \%$ ) and 43\% (95\% CI: 20-72\%), respectively, compared to non-snoring. Only in women who were $\geq 10$ years postmenopausal had a statistical association between frequent snoring and diabetes, with a 54\% (95\% CI: 23-92\%) increased odds of diabetes, compared to women who did not snore.

Conclusion: Snoring frequency is positively associated with diabetes. Women who snore frequently before and for at least ten years after menopause are at higher risk of developing diabetes. Frequent snorers and long-term postmenopausal women should monitor blood glucose levels to aid in the early detection and treatment of diabetes.
\end{abstract}

Keywords: Chinese Han population, diabetes, menopause, snoring

\section{Introduction}

Around 463 million people worldwide had diabetes in 2019, with China leading the way. ${ }^{1}$ Diabetes prevalence has steadily increased in China over the years, rising from $10.9 \%$ in 2013 to $12.8 \%$ in 2018. ${ }^{2,3}$ Diabetes is gender specific. While men are more likely than women to develop diabetes, the reverse is true for those over the age of 60 years. ${ }^{4}$ Concerns about the potential risk of diabetes in older women are warranted.

Research on risks of diabetes has primarily concentrated on health-related behaviors such as diet and physical activity. Self-reported snoring, on the other hand, is often overlooked. Snoring is not only a major manifestation of sleep apnea syndrome, but also has been linked to a variety of health problems in its own right. Epidemiological evidence showed that snoring plays a role in various diseases, such as hypertension, ${ }^{5}$ cardiovascular diseases, ${ }^{6}$ chronic kidney disease, ${ }^{7}$ and other diseases. ${ }^{8}$ While several studies indicate that snoring is associated with diabetes, ${ }^{9,10}$ there is some controversy regarding these findings. After adjusting for confounders of obesity and other chronic diseases in several studies, the snoring-diabetes association was limited to the female population. ${ }^{11,12}$ Menopause, as a critical reproductive transition in women, causes a tremendous endocrine shift in the body. Postmenopausal status is associated with diabetes regardless of 
age. ${ }^{13,14}$ Yet few studies have taken menopause into account when exploring the relationship between snoring and diabetes.

This study examined the relationship between snoring frequency and diabetes, as well as the effect of menopausal statuses and postmenopausal years.

\section{Methods}

\section{Participants and Design}

This study was conducted in Chongqing province as part of the China Multi-Ethnic Cohort (CMEC) study. The cohort's design and demographic-sociological characteristics have been described in detail elsewhere. ${ }^{15}$ Between August 2018 and January 2019, a baseline survey recruited 12,409 Chinese Han women aged 30 to 79 years in 13 districts or counties of Chongqing. Participants were excluded because of a deficiency in physical examination data (158), a deficiency in reproductive information (9), and abnormal or missing values (25). The final sample size was 12,218. Approval was received from the Ethics Committee of Sichuan University (No. K2016038). Written informed consent forms were accepted by all participants.

\section{Data Collection}

Face-to-face questionnaires were administered by trained investigators using tablets and uploaded to the system. The questionnaire content and recordings were then randomly checked for quality control by trained post-graduates. Physical examinations were tested by trained medical personnel following a standard protocol. Biological samples were sent to a third-party laboratory (Chongqing Dean Medical Laboratory Center Co., Ltd.) for uniform testing and feedback.

\section{Diabetes}

In this study, women were diagnosed with diabetes if they met any of the following items: ever received a physician diagnosis of diabetes, or fasting plasma glucose $(\mathrm{FBG}) \geq 7.0 \mathrm{mmol} / \mathrm{L}$, or glycated hemoglobin $(\mathrm{HbA} 1 \mathrm{c}) \geq 6.5 \%{ }^{16}$

\section{Snoring}

Self-reported snoring was obtained by questionnaire. Participants were asked, "Do you snore when you sleep?" Nonsnoring women were defined as those who did not snore or were unaware of their snoring status. Snoring frequency was also asked and classified among those who snored as "sometimes snoring" or "frequent snoring."

\section{Menopause}

The participants' current menstrual status was classified as "regular," "irregular," "perimenopausal," or "menopausal." Those who had menopause for at least 12 months were classified as "postmenopausal," while those who had menopause for less than 12 months were classified as "premenopausal." Additionally, they were asked their age at menopause if they were postmenopausal. The menopausal years were defined as the period between the survey and the age of menopause, and were classified as " $<10$ years" and " $\geq 10$ years."

\section{Covariables}

The following covariates were considered in this study: age, education level (primary school or below, junior middle school, junior high school or above), marital status (married/cohabiting, others), annual household income ( $<20 \mathrm{k}, 20 \mathrm{k}-$ $<60 \mathrm{k}, \geq 60 \mathrm{k}$ ), family history of diabetes (no, yes), exercise (never or hardly, occasionally or sometimes, often or everyday), alcohol drinking (never or hardly, occasionally or sometimes, often or everyday), smoking (never, ever/ current), sleep duration $(<7,7-<8,8-<9, \geq 9)$, hypertension, dyslipidemia, body mass index, and abdominal obesity. Family history of diabetes was defined as having diabetes in any member of the respondent's first-degree relatives (parents or siblings). ${ }^{17}$ Women were classified as having hypertension based on a physician diagnosis or three consecutive measurements of systolic or diastolic blood pressure of $\geq 140 \mathrm{mmHg} / 90 \mathrm{mmHg}$ were classified as having hypertension. ${ }^{18}$ Participants were classified as having dyslipidemia if triglyceride (TG) $\geq 2.3 \mathrm{mmol} / \mathrm{L}$, or low-density 
lipoprotein cholesterol (LDLC) $\geq 4.1 \mathrm{mmol} / \mathrm{L}$, or high-density lipoprotein cholesterol (HDLC) $<1.0 \mathrm{mmol} / \mathrm{L}$, or total cholesterol (TC) $\geq 6.22 \mathrm{mmol} / \mathrm{L} .{ }^{19}$ Body mass index (BMI) was calculated using the height and weight records from physical examinations $\left(\mathrm{kg} / \mathrm{m}^{2}\right)$, and divided into three groups according to Chinese guidelines: (1) underweight/normal weight: BMI $<24 \mathrm{~kg} / \mathrm{m}^{2}$; (2) overweight: BMI of $24-27.9 \mathrm{~kg} / \mathrm{m}^{2}$; (3) general obesity: BMI $\geq 28 \mathrm{~kg} / \mathrm{m}^{2}{ }^{20}$ Abdominal obesity was defined as women with a waist circumference $\geq 80 \mathrm{~cm}^{20}$

\section{Statistical Analysis}

SPSS 25.0 was performed for statistical analysis. The continuous and categorical variables were expressed as median (interquartile range) and number (percentage), corresponding to the Kruskal-Wallis $H$-test and the Chi-square test in oneway analysis of variance. To estimate the relationship between snoring frequency and diabetes, logistic regression was used to calculate the odds ratios (ORs) and their 95\% confidence intervals (CIs). Further subgroup analysis was performed to compare the differences between menopausal status groups. The significance was set as bilateral $P<0.05$.

\section{Results}

\section{Baseline Characteristics}

The characteristics of women classified according to snoring frequency are displayed in Table 1. Of the 12,218 women, $2880(23.6 \%)$ snored sometimes, while 1772 (14.1\%) snored frequently. Significant differences in age, education level, marital status, annual household income, family history of diabetes, exercise, alcohol drinking, smoking, sleep duration, hypertension, dyslipidemia, body mass index, and abdominal obesity were found between the snoring frequency groups $(P<0.05)$.

\section{Prevalence of Diabetes in Women by Snoring Frequencies}

Diabetes prevalence in women with varying snoring frequencies, stratified by menopausal status and menopausal years, is shown in Table 2. In both pre- and postmenopausal women, those who frequently snored had the highest prevalence of diabetes, followed by those who sometimes snored $(P<0.001)$. The same findings were observed in subgroups of menopausal years $(P<0.001)$.

\section{Association Between Diabetes and Snoring Among Pre- and Postmenopausal Women}

The association between diabetes and snoring using logistic regression is listed in Table 3. After adjusting for confounders, the odds of diabetes increased with the snoring frequency. And the odds ratios diminished with stepwise adjustment. The fully adjusted odds ratios of sometimes snoring and frequently snoring were 1.23 (95\% CI:1.05-1.43) and 1.47 (95\% CI:1.25-1.73) in model 4, respectively, compared to those who did not snore.

The subgroup analysis of snoring frequency and diabetes in women with various menopausal statuses and years of menopause is shown in Figure 1. In both premenopausal and postmenopausal women, snoring frequently was associated with a higher adjusted odds of diabetes than non-snoring. With stepwise adjustment, the odds ratios decreased to 1.58 (95\% CI: $1.07-2.32)$ and 1.43 (95\% CI: 1.20-1.72) in the final model. However, sometimes snoring failed to attain a significant association with diabetes after adjusting for abdominal obesity and body mass index. Among postmenopausal women, a statistical association between frequent snoring and diabetes was found only in the group with $\geq 10$ years of menopause in the final model ( $\mathrm{OR}=1.54,95 \%$ CI: 1.23-1.92). In women less than ten years postmenopausal, the statistical significance of frequent snoring was attenuated by abdominal obesity and body mass index (OR=1.18, 95\% CI: 0.86-1.63).

\section{Discussion}

Sleep is a critical health-related behavior. Sleep duration is linked to a variety of health problems, and the quality of sleep should be considered, including snoring. ${ }^{21}$ In this cross-sectional study, the odds of diabetes increased with the snoring frequency, even after adjustment for confounders. Frequent snoring is associated with diabetes in premenopausal women and women ten years or more after menopause. 
Table I Characteristics of Women by Groups of Snoring Frequency

\begin{tabular}{|c|c|c|c|c|c|}
\hline \multirow[t]{2}{*}{ Variables } & \multicolumn{3}{|c|}{ Snoring Frequency } & \multirow[t]{2}{*}{$\chi^{2} / H$} & \multirow[t]{2}{*}{$P^{a}$} \\
\hline & No $(n=7616)$ & Sometimes $(n=2880)$ & Frequently $(n=1772)$ & & \\
\hline Age (years) & $47(40,55)$ & $51(45,61)$ & $56(49,65)$ & $750.69^{\mathrm{b}}$ & $<0.001$ \\
\hline $\begin{array}{l}\text { Education level, } \mathrm{n}(\%) \\
\text { Primary school or below } \\
\text { Junior middle school } \\
\text { Junior high school or above }\end{array}$ & $\begin{array}{l}2591(34.0) \\
2401(31.5) \\
2624(34.5)\end{array}$ & $\begin{array}{l}980(34.0) \\
895(31.1) \\
1005(34.9)\end{array}$ & $\begin{array}{l}858(49.8) \\
520(30.2) \\
344(20.0)\end{array}$ & $199.81^{\mathrm{C}}$ & $<0.001$ \\
\hline $\begin{array}{l}\text { Marital status, } \mathrm{n}(\%) \\
\text { Married/cohabited } \\
\text { Others }\end{array}$ & $\begin{array}{l}6656(87.4) \\
960(12.6)\end{array}$ & $\begin{array}{l}2421(84.1) \\
459(15.9)\end{array}$ & $\begin{array}{l}1391 \text { (80.8) } \\
331(19.2)\end{array}$ & $58.11^{\mathrm{C}}$ & $<0.001$ \\
\hline $\begin{array}{l}\text { Annual household income [CNY], } n(\%) \\
<20 \mathrm{k} \\
20 \mathrm{k}-<60 \mathrm{k} \\
\geq 60 \mathrm{k}\end{array}$ & $\begin{array}{l}1815(23.8) \\
2662(35.0) \\
3139(41.2)\end{array}$ & $\begin{array}{l}677(23.5) \\
1012(35.1) \\
1191(41.4)\end{array}$ & $\begin{array}{l}487(28.3) \\
645(37.5) \\
590(34.3)\end{array}$ & $33.09^{c}$ & $<0.001$ \\
\hline $\begin{array}{l}\text { Family history of diabetes, } \mathrm{n}(\%) \\
\text { No } \\
\text { Yes }\end{array}$ & $\begin{array}{l}6934(91.0) \\
682(9.0)\end{array}$ & $\begin{array}{l}2538 \text { (88.1) } \\
342(11.9)\end{array}$ & $\begin{array}{l}1478(85.8) \\
244(14.2)\end{array}$ & $50.14^{c}$ & $<0.001$ \\
\hline $\begin{array}{l}\text { Exercise, } \mathrm{n}(\%) \\
\text { Never or hardly } \\
\text { Occasionally or sometimes } \\
\text { Often or every day }\end{array}$ & $\begin{array}{l}3183(41.8) \\
1602(21.0) \\
2831(37.2)\end{array}$ & $\begin{array}{l}1028(35.7) \\
567(19.7) \\
1285(44.6)\end{array}$ & $\begin{array}{l}737(42.8) \\
209(12.1) \\
776(45.1)\end{array}$ & $120.62^{c}$ & $<0.001$ \\
\hline $\begin{array}{l}\text { Alcohol drinking, } \mathrm{n}(\%) \\
\text { Never or hardly } \\
\text { Occasionally or sometimes } \\
\text { Often or every day }\end{array}$ & $\begin{array}{l}4770(62.6) \\
2576(33.8) \\
270(3.5)\end{array}$ & $\begin{array}{l}\text { I58I (54.9) } \\
1158(40.2) \\
141(4.9)\end{array}$ & $\begin{array}{l}1058(61.4) \\
539(31.3) \\
125(7.3)\end{array}$ & $99.30^{c}$ & $<0.001$ \\
\hline $\begin{array}{l}\text { Smoking, n (\%) } \\
\text { Never } \\
\text { Ever/current }\end{array}$ & $\begin{array}{l}7521 \text { (98.8) } \\
95(1.2)\end{array}$ & $\begin{array}{l}2821(98.0) \\
59(2.0)\end{array}$ & $\begin{array}{l}1690(98.1) \\
32(1.9)\end{array}$ & $10.46^{\mathrm{c}}$ & 0.005 \\
\hline $\begin{array}{l}\text { Sleep duration [hours], } \mathrm{n}(\%) \\
\quad<7 \\
7-<8 \\
8-<9 \\
\geq 9\end{array}$ & $\begin{array}{l}2000(26.3) \\
2105(27.7) \\
2655(34.9) \\
848(11.1)\end{array}$ & $\begin{array}{l}935(32.5) \\
802(27.9) \\
847(29.4) \\
293(10.2)\end{array}$ & $\begin{array}{l}634(36.9) \\
437(25.4) \\
480(27.9) \\
169(9.8)\end{array}$ & $106.27^{c}$ & $<0.001$ \\
\hline $\begin{array}{l}\text { Hypertension, n (\%) } \\
\text { No } \\
\text { Yes }\end{array}$ & $\begin{array}{l}5710(75.0) \\
1906(25.0)\end{array}$ & $\begin{array}{l}1888(65.6) \\
992(34.4)\end{array}$ & $\begin{array}{l}825(47.9) \\
897(52.1)\end{array}$ & $500.57^{c}$ & $<0.001$ \\
\hline $\begin{array}{l}\text { Dyslipidemia, n (\%) } \\
\text { No } \\
\text { Yes }\end{array}$ & $\begin{array}{l}6033(79.2) \\
1583(20.8)\end{array}$ & $\begin{array}{l}2060(71.5) \\
820(28.5)\end{array}$ & $\begin{array}{l}1014(58.9) \\
708(41.1)\end{array}$ & $323.83^{c}$ & $<0.001$ \\
\hline $\begin{array}{l}\text { BMI }\left[\mathbf{k g} / \mathbf{m}^{2}\right], \mathrm{n}(\%) \\
\text { Underweight/normal weight } \\
\text { Overweight } \\
\text { General obesity }\end{array}$ & $\begin{array}{l}4400(57.8) \\
2561(33.6) \\
655(8.6)\end{array}$ & $\begin{array}{l}1242(43.1) \\
1204(41.8) \\
434(15.1)\end{array}$ & $\begin{array}{l}433(25.1) \\
767(44.5) \\
522(30.3)\end{array}$ & $913.68^{c}$ & $<0.001$ \\
\hline $\begin{array}{l}\text { Abdominal obesity, n (\%) } \\
\text { No } \\
\text { Yes }\end{array}$ & $\begin{array}{l}4176(54.8) \\
3440(45.2)\end{array}$ & $\begin{array}{l}\mid 209(42.0) \\
|67|(58.0)\end{array}$ & $\begin{array}{l}393(22.8) \\
1329(77.2)\end{array}$ & $619.96^{\mathrm{C}}$ & $<0.001$ \\
\hline
\end{tabular}

Notes: ${ }^{a}$ The overall difference of snoring frequency among the three groups. ${ }^{b} \mathrm{Age}$ was expressed as median (interquartile range) and tested by Kruskal-Wallis $\mathrm{H}$-test. ${ }^{\mathrm{C}}$ Categorical variables were tested by the Chi-square test.

Abbreviation: BMI, body mass index. 
Table 2 Prevalence of Diabetes in Pre- and Post-Menopausal Women by Snoring Frequencies

\begin{tabular}{|l|c|c|c|c|}
\hline \multirow{2}{*}{ Snoring Frequency } & \multicolumn{2}{|c|}{ Menopausal Status } & \multicolumn{2}{c|}{ Menopausal Years } \\
\cline { 2 - 5 } & Pre (n=65 I4) & Post (n=5704) & $<10$ (n=2639) & $\geq 10(\mathbf{n = 3 0 6 5 )}$ \\
\hline No & $144(3.1)$ & $415(14.2)$ & $137(9.6)$ & $278(18.5)$ \\
Sometimes & $68(5.1)$ & $257(16.6)$ & $86(12.1)$ & $171(20.4)$ \\
Frequently & $48(9.6)$ & $289(23.6)$ & $82(16.4)$ & $207(28.7)$ \\
\hline$\chi^{2}$ & 55.69 & 55.62 & 17.11 & 30.76 \\
P & $<0.001$ & $<0.001$ & $<0.001$ & $<0.001$ \\
\hline
\end{tabular}

Notes: ${ }^{a}$ Data were presented as $\mathrm{n}(\%)$, representing the number (prevalence) of diabetes.

Table 3 Logistic Regression of Relationship Between Diabetes and Snoring Frequency

\begin{tabular}{|c|c|c|c|c|c|}
\hline & \multicolumn{5}{|c|}{ ORs (95\% Cls) } \\
\hline & Crude Model & Model I & Model 2 & Model 3 & Model 4 \\
\hline \multicolumn{6}{|c|}{ Snoring frequency } \\
\hline No & Ref & Ref & Ref & Ref & Ref \\
\hline Sometimes & $1.61(1.39-1.86)^{*}$ & $1.34(1.16-1.56)^{*}$ & $1.35(1.16-1.58)^{*}$ & $1.29(1.1 \mathrm{I}-\mathrm{I} .5 \mathrm{I})^{* *}$ & $1.23(1.05-1.43)^{* * *}$ \\
\hline Frequently & $3.07(2.65-3.56)^{*}$ & $2.05(1.76-2.39)^{*}$ & 1.95 (1.67-2.29)* & $1.66(1.4|-| .95)^{*}$ & $1.47(1.25-1.73)^{*}$ \\
\hline
\end{tabular}

Notes: $* \mathrm{P}<0.001, * * \mathrm{P}<0.01$, $* * * \mathrm{P}<0.05$. Model I: adjusted for age; Model 2: adjusted for model I plus education level, marital status, annual family income, exercise, alcohol drinking, smoking, family history of diabetes, sleep duration, and menopausal status; Model 3: adjusted for model 2 plus hypertension and dyslipidemia; Model 4: adjusted for model 3 plus abdominal obesity and body mass index.

Abbreviations: Ref, reference; OR, odds ratio; $\mathrm{Cl}$, confidence interval.

Our findings are concordant with those of previous research. We discovered that women who snored sometimes or frequently had a $23 \%$ (95\% CI: 5-43\%) and 47\% (95\% CI: $25-73 \%)$ increased odds of diabetes, respectively. A study conducted in Northern Sweden as part of the World Health Organization (WHO) study found that habitual snoring increased the risk of diabetes in females by 58\% (95\% CI: 2-244\%); no such association was found in males. ${ }^{12}$ The preceding study classified snoring into two categories (habitual and non-snoring), but we discussed the effect of snoring frequency further. In a study of Japanese seniors aged $\geq 65$ years, it was discovered that women with elevated snoring frequency had a higher risk of diabetes, whereas this correlation was only seen in men without obesity. ${ }^{22}$ The preceding study enrolled only older adults, whereas our study included individuals aged 30-79 years and found comparable results after age adjustment. Our analysis also controlled for abdominal obesity and body mass index in women, and the snoringdiabetes association remained strong. Additionally, a linear trend in hemoglobin A1c (HbAlc) level by increased snoring frequency was evaluated only in women at the baseline of a Korean cohort study. ${ }^{23}$ Snoring, on the other hand, was found to be independently associated with diabetes in two reports from the China Kadoorie Biobank cohort, regardless of gender. ${ }^{9,24}$ The controversy surrounding these studies in gender may be due to differences in race, lifestyles, study design, classification of snoring and diabetes, or it may be related to female factors, such as menopause. Nonetheless, a meta-analysis of eight observational studies summarized an association between habitual snoring and diabetes with pooled increased risk of 59\% (95\% CI: 20-211\%) in females, but not significant in males. ${ }^{25}$ In light of the above findings that the snoring-diabetes association is more prevalent in women, we included only female individuals to explore menopausal factors that are absent in men but critical in women.

In the present study, menopause is a significant confounder in the association between snoring and diabetes, which has garnered less attention in prior research. Women who snore regularly have $58 \%$ and $43 \%$ increased odds of developing diabetes before and after menopause [OR=1.58, 95\% CI:1.07-2.32; OR=1.43, 95\% CI:1.20-1.72]. Snoring frequently has a significant impact on diabetes, particularly in premenopausal women. Additionally, the analysis also revealed a statistical correlation between habitual snoring and elevated $\mathrm{HbAlc}$ levels solely in premenopausal women. ${ }^{26}$ Although this study used a different classification of snoring and different indicators for diabetes, these findings suggest 


\begin{tabular}{|c|c|c|c|c|}
\hline \multirow{2}{*}{$\frac{\text { Subgroups }}{\text { Menopausal status }}$} & Sometimes snoring & \multicolumn{3}{|c|}{ Frequently snoring } \\
\hline & & & & \\
\hline \\
\hline Model 1 & $1.57(1.16-2.11)$ & $\longmapsto$ & $2.58(1.82-3.66)$ & \\
\hline Model 2 & $1.64(1.21-2.22)$ & $\longmapsto$ & $2.54(1.78-3.63)$ & \\
\hline Model 3 & $1.43(1.04-1.95)$ & $\longmapsto$ & $1.82(1.25-2.65)$ & $\longmapsto$ \\
\hline Model 4 & $1.31(0.95-1.79)$ & $\longmapsto$ & $1.58(1.07-2.32)$ & $\longmapsto$ \\
\hline \multicolumn{5}{|l|}{ Post } \\
\hline Model 1 & $1.22(1.03-1.45)$ & $H$ & $1.82(1.53-2.16)$ & $\mapsto$ \\
\hline Model 2 & $1.24(1.04-1.48)$ & $\rightarrow-1$ & $1.78(1.50-2.12)$ & $\mapsto$ \\
\hline Model 3 & $1.22(1.02-1.46)$ & $\Leftrightarrow$ & $1.58(1.32-1.89)$ & $\mapsto$ \\
\hline Model 4 & $1.18(0.98-1.41)$ & $\because$ & $1.43(1.20-1.72)$ & $H-1$ \\
\hline \multicolumn{5}{|l|}{ Menopausal years } \\
\hline \multicolumn{5}{|l|}{$<10$} \\
\hline Model 1 & $1.28(0.96-1.70)$ & $\longmapsto$ & $1.76(1.31-2.37)$ & $\longmapsto$ \\
\hline Model 2 & $1.34(0.995-1.80)$ & $\mapsto$ & $1.67(1.24-2.27)$ & $\longmapsto$ \\
\hline Model 3 & $1.30(0.96-1.75)$ & $\longmapsto$ & $1.39(1.02-1.90)$ & $\mapsto$ \\
\hline Model 4 & $1.23(0.91-1.67)$ & $\mapsto$ & $1.18(0.86-1.63)$ & $\mapsto$ \\
\hline \multicolumn{5}{|l|}{$\geq 10$} \\
\hline Model 1 & $1.22(1.03-1.45)$ & $\mapsto-1$ & $1.82(1.53-2.16)$ & $\mapsto$ \\
\hline Model 2 & $1.24(1.04-1.48)$ & $\mapsto$ & $1.78(1.50-2.12)$ & $\mapsto-$ \\
\hline Model 3 & $1.16(0.93-1.45)$ & $\mapsto$ & $1.64(1.32-2.03)$ & $\mapsto$ \\
\hline \multirow[t]{2}{*}{ Model 4} & $1.13(0.91-1.42)$ & $\mapsto$ & $1.54(1.23-1.92)$ & $\mapsto$ \\
\hline & 0.5 & $\begin{array}{ccccc} & 1 & 1 & 1 & \\
1 & 1.5 & 2 & 2.5 & 3\end{array}$ & 0.5 & $\begin{array}{cccc} & 1 & 1 & 1 \\
1 & 1.5 & 2 & 2.5\end{array}$ \\
\hline
\end{tabular}

Figure I Subgroup analysis of association between snoring frequency and diabetes.

Notes: "No snoring" was taken as the reference group. The black squares present the odds ratios, and the black bounded horizontal lines present the $95 \%$ confidence intervals of the odds ratios. The gray vertical lines present the reference with the odds ratio of I. Model I: adjusted for age; Model 2: adjusted for model I plus education level, marital status, annual family income, exercise, alcohol drinking, smoking, family history of diabetes, and sleep duration; Model 3: adjusted for model 2 plus hypertension and dyslipidemia; Model 4: adjusted for model 3 plus body mass index and abdominal obesity.

that premenopausal women who snore frequently should not disregard changes in blood glucose. Meanwhile, regular snoring was associated with an increased odds of diabetes in women only if they had been menopausal for ten years or more (OR=1.54, 95\% CI:1.23-1.92). While this association was attenuated by obesity in women less than ten years postmenopausal. An analysis of a sample of 4436 women found that menopause duration of 10 years or more was at risk for hyperglycemia, whereas no such relationship was observed for menopausal years of less than $10 .^{27}$ Another research discovered a positive correlation between years since menopause and diabetes. ${ }^{28}$ This suggests that long-term menopausal women should be concerned about blood glucose, particularly those who snored frequently. In addition, we also found that the difference in diabetes between sometimes snoring and non-snoring was close to being significant after adjusting for abdominal obesity and overall obesity among both pre- and postmenopausal women [OR $=1.31,95 \%$ CI: 0.95-1.79; OR=1.18, 95\% CI: 0.98-1.41]. An analysis of 56,032 diabetes patients also found that body mass index, waist circumference, and other health-related behaviors mitigated the association between sometimes snoring and wellcontrolled glycemic. ${ }^{29}$ This indicates that the relationship between sometimes snoring and diabetes may be mainly influenced by obesity.

The mechanisms by which snoring contributes to the development of diabetes in women with menopausal statuses remain unclear. Snoring is considered to be the main manifestation of sleep apnea and shares similar mechanisms. Intermittent hypoxia alters sympathetic hyperactivity, oxidative stress, and inflammatory responses, ${ }^{30,31}$ all of which contribute to insulin resistance. ${ }^{32-34}$ These mechanisms may be the presumption that snoring relates to the higher prevalence of diabetes. The effect of menopause on diabetes may be related to the response caused by its hormonal alterations. Additionally, the decrease of estrogen secretion in postmenopausal individuals leads to endocrine alterations associated with insulin resistance. ${ }^{35}$ A systematic review concluded that hormone therapy after menopause was linked to lower rates of diabetes and improved glycemic control. ${ }^{36}$ Meanwhile, menopause may cause peripheral fat to accumulate in the trunk, leading to abdominal obesity, ${ }^{37}$ which may lead to insulin resistance. ${ }^{38}$ With the aforementioned studies, we hypothesize that the role of menopause in the snoring-diabetes relationship may be related to its resultant obesity. Furthermore, further research into the effect of sex hormones on the snoring-diabetes association would be beneficial. 
Our study used cross-sectional data from a large-scale cohort study in Chongqing that was subjected to stringent quality control and had a high level of representativeness. As far as we know, the study is the first to investigate the association between diabetes and snoring in Chongqing, one of the four Municipalities located in southwestern China. Since some studies have found the snoring-diabetes association in women only, ${ }^{11,12,25}$ we concentrated on the effect of menopausal status in addition to comprehensive consideration of potential confounders that may be less considered in other studies. Additionally, to account for the effect of ethnic background on the results, ${ }^{39}$ only the Chinese Han population was included in our study. There are, however, some limitations. First, using the baseline portion of the cohort, we cannot infer a causal affiliation between diabetes with snoring and menopause. Second, because snoring, family history of diabetes, and menopause-related variables were self-reported, recall bias could not be avoided. Snorers who sleep alone may not be aware of their snoring status. This misclassification may underestimate the snoring-diabetes association. However, a previous study found a significant correlation between self-reported snoring and objectively recorded snoring, with a sensitivity of $94 \%$ and a specificity of $58 \% .{ }^{40}$ Women may be unaware that they have diabetes in the presence of their first-degree relatives. However, a previous study found that respondents' self-reported family history of diabetes had a sensitivity of $89.2 \%$ and a specificity of $81.0 \%$ when compared to first-degree relatives' self-reported personal diabetes. ${ }^{41}$ Thirdly, we lack information on the distinction between type 2 diabetes and type 1 diabetes. Despite this, type 1 diabetes affects only $5.49 \%$ of the diabetic population in China. ${ }^{42}$ Finally, although potential confounding factors were adjusted, there were no concerns about drugs or surgeries that affect female hormones, such as natural or artificial menopause or hormone replacement therapy.

\section{Conclusion}

Snoring frequency is positively associated with diabetes. Women who snore frequently before and for ten years or more after menopause are at higher risk of developing diabetes. Frequent snorers and long-term postmenopausal women should monitor blood glucose to aid in the early detection and treatment of diabetes.

\section{Acknowledgments}

We are grateful to all participants and all team members for their support for this study.

\section{Funding}

This work was supported by the National Key R\&D Program of China (grant numbers: 2017YFC0907303).

\section{Disclosure}

The authors report no competing interest in this work.

\section{References}

1. Saeedi P, Petersohn I, Salpea P, et al. Global and regional diabetes prevalence estimates for 2019 and projections for 2030 and 2045: results from the International Diabetes Federation Diabetes Atlas, 9(th) edition. Diabetes Res Clin Pract. 2019;157:107843. doi:10.1016/j.diabres.2019.107843

2. Wang L, Gao P, Zhang M, et al. Prevalence and ethnic pattern of diabetes and prediabetes in China in 2013. JAMA. 2017;317(24):2515-2523. doi:10.1001/jama.2017.7596

3. Li Y, Teng D, Shi X, et al. Prevalence of diabetes recorded in mainland China using 2018 diagnostic criteria from the American Diabetes Association: national cross sectional study. BMJ. 2020;369:m997. doi:10.1136/bmj.m997

4. Yang W, Lu J, Weng J, et al. Prevalence of diabetes among men and women in China. N Engl J Med. 2010;362(12):1090-1101. doi:10.1056/ NEJMoa0908292

5. Khazaie H, Negahban S, Ghadami MR, Sadeghi Bahmani D, Holsboer-Trachsler E, Brand S. Among middle-aged adults, snoring predicted hypertension independently of sleep apnoea. J Int Med Res. 2018;46(3):1187-1196. doi:10.1177/0300060517738426

6. Wei Y, Lv J, Guo Y, et al. Age-specific associations between habitual snoring and cardiovascular diseases in China: a 10-Year Cohort Study. Chest. 2021;160(3):1053-1063. doi:10.1016/j.chest.2021.04.070

7. Song J, Wang C, Ma A, et al. Self-reported snoring is associated with chronic kidney disease independent of metabolic syndrome in middle-aged and elderly Chinese. J Diabetes Investig. 2019;10(1):124-130. doi:10.1111/jdi.12855

8. Yunus FM, Khan S, Mitra DK, Mistry SK, Afsana K, Rahman M. Relationship of sleep pattern and snoring with chronic disease: findings from a nationwide population-based survey. Sleep Health. 2018;4(1):40-48. doi:10.1016/j.sleh.2017.10.003

9. Dai N, Shi Q, Hua Y, et al. Snoring frequency and risk of type 2 diabetes mellitus: a prospective cohort study. BMJ Open. 2021;11(5):e042469. doi:10.1136/bmjopen-2020-042469 
10. Cho SMJ, Lee H, Shim JS, Kim HC. Association of snoring with prediabetes and type 2 diabetes mellitus: the cardiovascular and metabolic diseases etiology research center cohort. Diabetes Metab J. 2020;44(5):687-698. doi:10.4093/dmj.2019.0128

11. Sabanayagam C, Teppala S, Shankar A. Markers of sleep disordered breathing and diabetes mellitus in a multiethnic sample of US adults: results from the national health and nutrition examination survey (2005-2008). Int J Endocrinol. 2012;2012:879134. doi:10.1155/2012/879134

12. Valham F, Stegmayr B, Eriksson M, Hägg E, Lindberg E, Franklin KA. Snoring and witnessed sleep apnea is related to diabetes mellitus in women. Sleep Med. 2009;10(1):112-117. doi:10.1016/j.sleep.2007.11.005

13. Ren Y, Zhang M, Liu Y, et al. Association of menopause and type 2 diabetes mellitus. Menopause. 2019;26(3):325-330. doi:10.1097/ GME.0000000000001200

14. Di Donato P, Giulini NA, Bacchi Modena A, et al. Risk factors for type 2 diabetes in women attending menopause clinics in Italy: a cross-sectional study. Climacteric. 2005;8(3):287-293. doi:10.1080/13697130500196866

15. Zhao X, Hong F, Yin J, et al. Cohort profile: the China Multi-Ethnic cohort (CMEC) study. Int J Epidemiol. 2021;50(3):721-7211. doi:10.1093/ije/ dyaa185

16. American Diabetes Association. 2. Classification and diagnosis of diabetes: standards of medical care in Diabetes-2018. Diabetes Care. 2018;41 (Suppl 1):S13-S27. doi:10.2337/dc18-S002

17. Hariri S, Yoon PW, Qureshi N, Valdez R, Scheuner MT, Khoury MJ. Family history of type 2 diabetes: a population-based screening tool for Prevention? Genet Med. 2006;8(2):102-108. doi:10.1097/01.gim.0000200949.52795.df

18. Chobanian AV, Bakris GL, Black HR, et al. The seventh report of the joint national committee on prevention, detection, evaluation, and treatment of high blood pressure: the JNC 7 report. JAMA. 2003;289(19):2560-2572. doi:10.1001/jama.289.19.2560

19. Pan L, Yang Z, Wu Y, et al. The prevalence, awareness, treatment and control of dyslipidemia among adults in China. Atherosclerosis. 2016;248:2-9. doi:10.1016/j.atherosclerosis.2016.02.006

20. Chen C, Lu FC. The guidelines for prevention and control of overweight and obesity in Chinese adults. Biomed Environ Sci. 2004;17 Suppl:1-36.

21. Sambou ML, Zhao X, Hong T, et al. Associations between sleep quality and health span: a prospective cohort study based on 328,850 UK biobank participants. Front Genet. 2021;12:663449. doi:10.3389/fgene.2021.663449

22. Wada H, Furuya S, Maruyama K, Ikeda A, Kondo K, Tanigawa T. Prevalence and clinical impact of snoring in older community-dwelling adults. Geriatr Gerontol Int. 2019;19(11):1165-1171. doi:10.1111/ggi.13763

23. Lee YH, Kweon SS, Choi JS, et al. A gender-specific association between self-reported snoring and hemoglobin Alc levels in a general population without type 2 diabetes mellitus. Yonsei Med J. 2017;58(6):1152-1159. doi:10.3349/ymj.2017.58.6.1152

24. Wei Y, Zheng B, Fan J, et al. Habitual snoring, adiposity measures and risk of type 2 diabetes in 0.5 million Chinese adults: a 10 -year cohort. $B M J$ Open Diabetes Res Care. 2020;8(1):e001015. doi:10.1136/bmjdrc-2019-001015

25. Xiong X, Zhong A, Xu H, Wang C. Association between self-reported habitual snoring and diabetes mellitus: a systemic review and meta-analysis. J Diabetes Res. 2016;2016:1958981. doi:10.1155/2016/1958981

26. Joo S, Lee S, Choi HA, et al. Habitual snoring is associated with elevated hemoglobin A1c levels in non-obese middle-aged adults. $J$ Sleep Res. 2006;15(4):437-444. doi:10.1111/j.1365-2869.2006.00556.x

27. Yan F, Liu J, Zhao X, et al. Association of the number of years since menopause with metabolic syndrome and insulin resistance in Chinese urban women. $J$ Women's Health. 2015;24(10):843-848. doi:10.1089/jwh.2014.5183

28. Wu HB, Wang H, Hu RY, et al. The association between sleep duration, snoring and prevalent type 2 diabetes mellitus with regard to gender and menopausal status: the CKB study in Zhejiang rural area, China. Acta Diabetol. 2017;54(1):81-90. doi:10.1007/s00592-016-0918-1

29. Wang T, Lu J, Wang W, et al. Sleep duration and snoring associate with hypertension and glycaemic control in patients with diabetes. Diabet Med. 2015;32(8):1001-1007. doi:10.1111/dme.12809

30. Lee EJ, Heo W, Kim JY, et al. Alteration of inflammatory mediators in the upper and lower airways under chronic intermittent Hypoxia: preliminary Animal Study. Mediators Inflamm. 2017;2017:4327237. doi:10.1155/2017/4327237

31. Iturriaga R, Moya EA, Del Rio R. Inflammation and oxidative stress during intermittent hypoxia: the impact on chemoreception. Exp Physiol. 2015;100(2):149-155. doi:10.1113/expphysiol.2014.079525

32. Wieser V, Moschen AR, Tilg H. Inflammation, cytokines and insulin resistance: a clinical perspective. Arch Immunol Ther Exp (Warsz). 2013;61 (2):119-125. doi:10.1007/s00005-012-0210-1

33. Esler M, Rumantir M, Wiesner G, Kaye D, Hastings J, Lambert G. Sympathetic nervous system and insulin resistance: from obesity to diabetes. Am J Hypertens. 2001;14(11 Pt 2):304S-309S. doi:10.1016/S0895-7061(01)02236-1

34. Luc K, Schramm-Luc A, Guzik TJ, Mikolajczyk TP. Oxidative stress and inflammatory markers in prediabetes and diabetes. J Physiol Pharmacol. 2019;70(6). doi:10.26402/jpp.2019.6.01

35. Golden SH, Dobs AS, Vaidya D, et al. Endogenous sex hormones and glucose tolerance status in postmenopausal women. J Clin Endocrinol Metab. 2007;92(4):1289-1295. doi:10.1210/jc.2006-1895

36. Szmuilowicz ED, Stuenkel CA, Seely EW. Influence of menopause on diabetes and diabetes risk. Nat Rev Endocrinol. 2009;5(10):553-558. doi:10.1038/nrendo.2009.166

37. Davis SR, Castelo-Branco C, Chedraui P, et al. Understanding weight gain at menopause. Climacteric. 2012;15(5):419-429. doi:10.3109/ 13697137.2012.707385

38. Kahn SE, Hull RL, Utzschneider KM. Mechanisms linking obesity to insulin resistance and type 2 diabetes. Nature. 2006;444(7121):840-846. doi:10.1038/nature 05482

39. Ong ZL, Chaturvedi N, Tillin T, Dale C, Garfield V. Association between sleep quality and type 2 diabetes at 20-year follow-up in the Southall and Brent REvisited (SABRE) cohort: a triethnic analysis. J Epidemiol Community Health. 2021;75(11):1117-1122. doi:10.1136/jech-2020-215796

40. Jennum P, Hein HO, Suadicani P, Gyntelberg F. Cardiovascular risk factors in snorers. A cross-sectional study of 3323 men aged 54 to 74 years: the Copenhagen Male Study. Chest. 1992;102(5):1371-1376. doi:10.1378/chest.102.5.1371

41. Janssens AC, Henneman L, Detmar SB, et al. Accuracy of self-reported family history is strongly influenced by the accuracy of self-reported personal health status of relatives. J Clin Epidemiol. 2012;65(1):82-89. doi:10.1016/j.jclinepi.2011.05.003

42. Tang X, Yan X, Zhou H, et al. Prevalence and identification of type 1 diabetes in Chinese adults with newly diagnosed diabetes. Diabetes Metab Syndr Obes. 2019;12:1527-1541. doi:10.2147/DMSO.S202193 


\section{Publish your work in this journal}

The International Journal of General Medicine is an international, peer-reviewed open-access journal that focuses on general and internal medicine, pathogenesis, epidemiology, diagnosis, monitoring and treatment protocols. The journal is characterized by the rapid reporting of reviews, original research and clinical studies across all disease areas. The manuscript management system is completely online and includes a very quick and fair peer-review system, which is all easy to use. Visit http://www.dovepress.com/testimonials.php to read real quotes from published authors.

Submit your manuscript here: https://www.dovepress.com/international-journal-of-general-medicine-journal 